\title{
Research on Volunteer Service System Construction of City Major Festival Activity: A Case of the Asia-Europe Exposition of Urumqi
}

\author{
Bin Wen ${ }^{1, a}$, Zhaoping Yang ${ }^{2, b,{ }^{*}}$, Qiling Huang ${ }^{3, c}$ \\ ${ }^{1}$ a Xinjiang Institute of Ecology and Geography, Chinese Academy of Science, Urumqi, Xinjiang \\ 830011, China \\ b College of Resource and Environment Sciences, Xinjiang University, Urumqi, 830046, China \\ c University of Chinese Academy of Science, Beijing, 100049, China
}

d Department of Economic Management, Huanghuai University, Zhumadian, 463000, China

e Tourism School, Xinjiang University of Finance \& Economics, Urumqi, 830012, China

${ }^{2}$ Xinjiang Institute of Ecology and Geography, Chinese Academy of Science, Urumqi, Xinjiang 830011, China

${ }^{3}$ Tourism School, Xinjiang University of Finance \& Economics, Urumqi, 830012, China

aemail:xjwenbin@163.com, $\begin{aligned} & \text { bemail: Yangzp@ms.xjb.ac.cn, *Corresponding author, ' }{ }^{\star} \text { email: } \\ & \text { ciracle@yahoo.com.cn }\end{aligned}$

Keywords: Volunteer Service System; Asia-Europe Exposition; Public Service of Tourism Festival Activity

\begin{abstract}
Exhibition tourism is an essential part of city tourism. In recent years, the successful held of a series of exhibition and events of major city in China have close relationship with the volunteer service. This text through the analysis of the questionnaire, on the basis of the condition of volunteer of public service of the Asia-Europe Exposition to find the shortcoming of volunteer service and put forward the relevant suggestions.
\end{abstract}

\section{Introduction}

With the gradual improvement of the exhibition tourism system, the volunteer service systems of public service of tourism is also gradually improving, and produce profound influences. The service quality of public service of tourism, to some extent, it can influence the held quality of exhibition tourism[1].

At present, Xinjiang has entered a new period of tourism development. The exhibition tourism of Xinjiang has brought enormous business opportunity to the rapid development of Xinjiang. Especially the annual Asia-Europe Exposition is a powerful window to propagandize Xinjiang to the world. The volunteer service in the public service has become a new attraction of exhibition tourism. The volunteer service system will be improved[2], and during all kinds of exhibition tourism, volunteer service will account for a large proportion of the public service system.

The volunteer tourism service started late in China, and now it is in the stage of beginning and development. So many mechanisms are not perfect in the volunteer tourism service system. Volunteers are the main power for the development of volunteer career at all times. There are some problems occurred during the Asia-Europe Exposition, which reflect the deficiencies of the volunteer service, and we will solve the problems pointedly. To improve the developing quality of tourism industry, satisfy the individual requests of tourists, improve the satisfaction of tourists and gradually improve the public tourist service system for the rapid development of Xinjiang tourism industry.

Public tourist service is an essential factor for the modern tourism industry. It is an important symbol to measure the development level of regional tourism, and also is an important indicator to measure the satisfaction of tourists for the specific tourism. Improving the public tourist service 
system can attracts more tourists.

Public tourist service is the extension of public service in the tourism areas. Li Shuang points out: public tourist service is the combination of which is given by government and other organizations, meeting the tourists' demands as the core, and not to make profits with the products and services of obvious publicity[3].

The volunteers are the people who attend the related organization voluntarily under their own condition allow and under the premise of not seeking any material, money and related benefits, make good use of the existing resources, and voluntary to sacrifice what you can devote, to implement service activity down-to-earth with the capacity of professional, skilled and long-term. The spirit of volunteer can be summed up eight characters: "contribution, love, mutual help and progress.

Voluntary supply refers to the third department represented by the organization of non-governmental groups( for instance non-profit and charity organization etc.) or a person who provides public service for the society not to make profits for the purpose, independent or half-dependent. Voluntary supply plays a good complimentary role in the governmental supply and marketing supply, and it is a civilization symbol to measure one country. Voluntary supply is a kind of style between government and market with the quality of volunteer, organization, non-profit and non-government.

\section{The Analysis of Voluntary Supply in Asia-Europe Exposition}

A. The Role Location and Service Content of Volunteer of Asia-Europe Exposition

China-Asia-Europe exposition is the inheritance and sublimation of Urumqi Foreign Economic and Trade Fair. The 19th held of Urumqi Foreign Economic and Trade Fair upgraded to China-Asia-Europe exposition, which is under the new situation the Party Central Committee and the State Council focus on further expand the pace of the opening up to the west and border open , speeding up the construction of our country will promote Xinjiang to the bridgehead of the west of the opening, to ensure that Xinjiang can realize the leaping development and stability which is a major strategic way to promote our country form a new pattern of opening-up of "continental open" and "coastal open", play a role of hub and bridgehead in the process of opening to the west in Xinjiang[4]. It is this event that fully embodies the importance role of volunteers. The volunteers' slogan of "Smile together, creating together" has shouted the volunteers' spirit of Asia-Europe Exposition.

The successful held of Asia-Europe Exposition needs the mutual efforts of thousands of volunteers. During the Asia-Europe Exposition, volunteers are the main power of the service supplier for the exposition and periphery . Volunteers provide consults and directions for the tourists and form a good social atmosphere for the non-profit tourism service through sincere service. College students are the main power of the public tourist service for the Asia-Europe Exposition, during the last exposition, the total number of volunteer is 11100 including three categories: the number of the former volunteer of committee is 100 , exposition volunteer is 1000 , and city volunteer is 10000 . The city volunteer has 30 branches of advocating service system, the total number is 900; the public bus station has 40 branches, total number is 600 . In the capital city, the major transportation hub, business cites, scenic spots, medical organization, hotel, culture square etc. important square or window industry to carry out the volunteer service of keeping the order, consulting information and civilized direction etc. Meanwhile there are 10 volunteer houses with 10 branches service team of fixed station, the total number is 300 .

During the process of making efforts, what the volunteers can gain is other's necessity and social recognition, which is nether the money nor the material rewards but is a kind of inner spirit value. The activity of volunteer service comes from society, when the volunteer do the voluntary jobs, they not only help others but also can learn new knowledge and skills to promote individual growth and personal improvement.

B. The Restrict Factors of Voluntary Supply in Asia-Europe exposition

Firstly, colleges and universities do not set up the relevant incentive mechanism for the 
volunteers. Colleges and universities should inspire the university students' innovation and make more students join in the army of volunteer through the relevant incentive mechanism. Secondly, there is no proper training course related to the volunteer when the colleges and universities set up the elective courses. As far as I am concerned, students should have the knowledge of contents of service for volunteer in class. Improve the serving skill of volunteer and make the students have the basic knowledge to deal with the emergency[5].

The organization department of volunteer has less skilled training for the volunteer, the weak intensity of protecting the volunteers' rights and profits, and more support to manage volunteer which has negative effects an the possibility for the volunteers' participation. There are some problems existing in fund raising: the capital of activity of volunteer service is less, besides the source of fund raising is single. The ability of social and personal fund raising is limited; the government has the larger pressure of support[6].

Management system of volunteer service is not perfect, some under the banner of volunteers engaged in the activities of but not volunteers, which blow the enthusiasm of volunteers. In some large public welfare activities, volunteers' service work is superficial and has strong political color, more often; volunteers often act as the role of cheap labor.

In terms of Asia-Europe exposition, the activity circle is short, and the single of service field blow the enthusiasm of the volunteers who can't meet the need of self-improvement, caused the high wastage rate of volunteers. Volunteers often hope to provide services in different fields for the people. Which not only can increase the enthusiasm of volunteers, also can better and more comprehensive exercise volunteers[7].

Because of the quality of the volunteers level is different, a few low quality level of the volunteers cause its own lack of honesty, and make a bad impression of tourists volunteers. Many volunteers' action mostly remain in the activity level, the activities of the occasional is more, while the persistent activity is less. Just in Urumqi, large activity is less, and many volunteers' participation in the time of activities is short, so does the number. Volunteers participate in activities mostly in the form of the activities which has neglected the deep excavation of the spirit of volunteers. Many volunteer organization form of activity is rigid, public welfare activities is not big, which is trapped in the position of in the activities and do activities. These superficial activities will impact the volunteer organization itself, and will have greater blow of enthusiasm of volunteers' service.

Volunteers use their own time, skills, knowledge and energy to serve the society and return the society, and they should get spiritual and material rewards. But a few volunteers for the purpose of utilitarianism distorted the connotation of the volunteer, distorted the cultural spirit of volunteer, which caused ill effect in university students. Leading to the appearance of the phenomenon of volunteers' irresponsibility.

Though the service enthusiasm of the volunteers was very high at the beginning of the exhibition, it then decreased after the training for several days. Even some volunteers couldn't insist it on, if they could, they did it barely. There are still gaps between self-expectation of the volunteers' and the reality.

\section{Investigation and Analysis}

A. The design of the questionnaire

In order to know well about the s condition of the service of the volunteers in the Asia-Europe Expo, to master accurately about the current situation and the existing problems, to enhance the overall quality, I make some enquiries to the students who are volunteers to see the problems they are meeting during their service. According to inquiry and reference materials, I design the questionnaires and spread them to the volunteers and on the Internet.

The number of the questionnaires giving out is 51 , valid ones 50 , volunteers 35 , the participants 15. The phenomenon of appearing the same answer sheet won't happen because the IP address is set unrepeated

In September, 2011, the first Asia-Europe Expo was held successfully in Urumqi in Xinjiang. 
Volunteers played important roles, but there are still some flaws in detail. In order to hold Expo in every next year smoothly, I hope the form of the questionnaires can collect the suggestions of yours, so that I can find the key points of the problems and think out the ways to enhance the overall quality of the service and optimize it.

B. Data Analysis

The discussion about whether it is necessary for the universities to provide the professional training course of volunteer, the questionnaire statistic of informants' shows:80\% informants think it is necessary for the universities to provide the professional training course of volunteer. They think it not only can help to improve the professional qualities of the university students, but benefit themselves as well.

When discussed about the strongest abilities of volunteers, the questionnaire statistic of informants shows: the training of the volunteers' abilities, the result shows: $48 \%$ informants think that the most important thing to become a volunteer is the spirit of dedication. As a volunteer, first of all, one should have the higher thoughts awareness, only in this way one can be faithful; $26 \%$ informants think that the most important thing is to pay close attention to the etiquette rules. The volunteers transmit the urban civilization while they help others. So the etiquette rules are very important ; $1 \%$ informants think that the most important thing is to master the knowledge about the traditional Chinese culture. And the volunteers should expertly master the methods of the first aid. $4 \%$ informants think the most important thing to be a volunteer is the good physical fitness and the good ability of foreign language.

The main way to get the capital of the service system which the volunteer participate in, the questionnaire statistic of informants' shows: $28 \%$ the volunteer service funds come from the public collection, $24 \%$ the volunteer service funds come from the government's grants. Thus it can be seen that the public collection has the large share while the government's grants also have the important function.

When survey the reason why the volunteers participate in the voluntary activities, the questionnaire statistic of informants: It can show the $90 \%$ majority of people participating in volunteer activities want to improve their practical ability, followed by expansion of interpersonal communication. Once again, an increase of knowledge, at the fair, volunteers are dealing with people from all walks of life, and they increase their knowledge in the process when communicate with people.

When asked the respondents what problems they confront in the current volunteer activities, analysis of the questionnaire: volunteer activities still has many problems. The histogram of the height difference is not big; we can see the problems are still relatively concentrated.

In the survey, the respondents want the government support the cause of volunteer service as shown below: Respondents hope that some organizations eligible for a certificate for free training for volunteers on a regular basis, in order to improve the trustworthiness of the volunteers. And hope that the relevant departments to develop laws and regulations to protect the vital interests of the volunteers.

When asked about what they have learned participating in the volunteer activities, the analysis as follows: Most students says they gained happiness, and the second is that their skills can be improved, which can not only have helped others, but also have improved ourselves. On the other hand, it also has shown the spiritual values of the A-E Expo volunteers, of which says: Smiling together, creating together.

\section{Conclusion and Discussion}

A. Problems existing among the A-E Expo volunteers' service

Analyzing according to the feedback of the questionnaires, there are 5 points of problems existing among the Asia-Europe Exposition volunteers service.

Volunteers lack of professional training, and several of them have the low quality of services, which have affected the enthusiasm of a few volunteers.

Legitimate rights and interests of volunteers cannot be guaranteed, so that a high loss rate of 
volunteers has happened.

Volunteers are of the unsound incentive mechanism.

Volunteers pay much attention to the superficial work only, and they have a short activity cycle.

The source of the fund of the activity is quite single, which has limited the content of the activity.

B. Settlement proposals to solve the problems among the A-E Expo volunteers service

Most of the A-E Expo volunteers are college and university students. As a result, we can offer some related curriculums in the courses of colleges and universities, to develop service awareness and skills of the volunteers in school. Ensure the legitimate rights and interests of the tourism service volunteers cannot be separated from improving laws and regulations as well as rectifying the tourism market. Government should strengthen their supervision so that the tourism can regulate the tourism business model depending on the power of the government and avoid the phenomenon that pretending to be a volunteer, but getting engaged in commercial activities. Thus effectively protect the legitimate rights and interests of volunteers. Establish the volunteers' incentives to stimulate the enthusiasm of the volunteer service. If the training organization can offer a free training with a certificate to volunteers on a regular basis, give appropriate guidance, train the volunteers to reflect the value of volunteering services, and increase the number of volunteers' supply and participation, the heavy wastage rate of volunteers will be improved a lot. Fund raising should widen capital investment channel, not only depend on the government and between the folk and other fund raising, if only by government and between the folk and other fund raising, then the voluntary service activities will be difficult to sustain for long. More should be from a single source to multiple funding sources development.

\section{Acknowledgement}

This paper was supported by Chinese Academy of Sciences Visiting Professorship for Senior International Scientists (project number: 2011T2Z42). The tourism administration of Xinjiang Uygur Autonomous Region provided great help during the surveys.

\section{References}

[1] Shuang Li and Fucai. Huang.Development of tourism public service connotation, characteristic and classification framework. [J]. Journal of tourism, 2010(356)23-25.

[2] Cun. Zhao and Jie. Wang. The connection of the implement of volunteer service activities an the improvement of the students' employment ability.[J].Jiangsu polytechnic college of agriculture and forestry, 2006(125)133-138.

[3] Jie. Li. The study of valuable meaning of college students volunteer service.[J]. Liaoning economic management cadre institute journal, 2009(56)223-225.

[4] Shuang. Li and Quying. Gan. The system of Tourism public service: A construction of theoretical frame.[J]. The Beijing second foreign language college journals, 2010(423) 213-216.

[5] Qun. Zhou.The analysis of behavior and treatment of the Olympic volunteer service, behavior and treatment of volunteer in 2008 Beijing Olympic Games .[J].Journal of Beijing Sport University, 2006(256)235-239.

[6] Lin. Zhang and Gan. Liu.Thinking about the problems of supply of the public service in city community .[J].Shandong Normal University press (Humanities and social science edition), 2007.

[7] He. Zhao.Practical exploration of improving employability of College students participating in volunteer service.[J].Heilongjiang higher education research, 2012(169)12-19. 